\title{
The Relationship between Knowledge Management and Organizational Performance of Malaysian Private Colleges: A Mediating Role of Managing Talent Practices
}

\author{
Khor Kok Keat", Abdullah Lin \\ Othman Yeop Abdullah Graduate School of Business, Universiti Utara Malaysia, Malaysia
}

Copyright $\mathrm{O} 2018$ by authors, all rights reserved. Authors agree that this article remains permanently open access under the terms of the Creative Commons Attribution License 4.0 International License

\begin{abstract}
Knowledge management plays a vital role in sustaining organizational performance of private academic institutions over time. Nonetheless the linkage between knowledge management, managing talent practices and organizational performance is not adequately addressed. This study therefore is aimed to investigate the relationship between knowledge management and organizational performance of Malaysian private colleges and whether managing talent practices, namely managing talent development and talent retention mediate the relationship between knowledge management and organizational performance of Malaysian private colleges. PLS-SEM technique is deployed to test the hypothesized relationships in the model. Data to all variables of interest studied is collected through a survey using structured questionnaires. A total of 785 sets of questionnaires was distributed to academic and non-academic staff above the executive level from 157 selected private colleges in Malaysia, out of which $243(31 \%)$ of them were valid and useable to this study. Empirical findings in this study highlight that knowledge management has a significant positive relationship with organizational performance of private colleges. Managing talent development rather than talent retention is found to have a significant direct positive influence on organizational performance of private colleges. In addition, knowledge management is predicted to have a significance positive influence on talent development and talent retention respectively. The mediation effects of talent development is statistically significant and in this regard, talent development is shown to have partially mediated the relationship between knowledge management and organizational performance of Malaysian private colleges. Both limitations and managerial implications are also highlighted in this paper.
\end{abstract}

Keywords Knowledge Management, Talent Development, Talent Retention, Organizational
Performance, PLS-SEM

\section{Introduction}

As Malaysia is making a transition from its production-based economy to a knowledge-based economy, the initiative of knowledge management among the Malaysian higher learning institutions is critically important to their organizational success (Nasiruzzaman, Qudaih \& Dahlan [1]; Nawaz \& Gomes [2]). In particular, several past studies (Mohamad, Manning \& Tatnall [3]; Attallah et al. [4]) have suggested that knowledge management has largely been accepted by the Malaysian public institutions of higher learning as a way to achieve better organizational outcomes. As the popularity of knowledge management within the country's higher educational organizations increases, they are further reported to have encountered barriers to managing their organizational knowledge-base in today's knowledge-intensive environment that essentially allows these learning organizations to realize competitive advantage in delivering a sustainable organizational performance (Norulkamar \& Hatamleh [5]; Aziz, Lotfi \& Dahlan [6]). However in the study of Yusoff, Mahmood and Jaafar [7], the practice of managing organizational knowledge-related activities in determining the business success of academic institutions in Malaysia still appears to be at its early stage.

A study by Demchig[8] has further suggested that higher educational institutions tend to neglect knowledge at the organizational level. From the business perspective, a systematic way of managing organizational knowledge among private colleges in Malaysia is paramount in fostering management and technical competencies to 
continuously thrive in this challenging economic environment. Other scholars such as Yeh [9] has indicated that while academic knowledge served the primary purpose of the institutions of higher learning, organizational knowledge is nonetheless crucial to the overall business success of the educational organizations. In this regard, private enterprise colleges in the country that are not able to keep pace with changes in knowledge are likely to have difficulties in sustaining their business success in the longer term.

In the effort to managing organizational knowledge resource, these local private colleges similar to other business organizations are assumed to drive the managing practices of developing and retaining its talented workforce deemed as intellectual assets to foster a competitive advantage for the betterment of their organizational performance. Past studies like Schroevers and Hendriks [10] claims such interconnection seems plausible since knowledge and human talent are closely related entities to firms performance and that by managing knowledge systematically induces these key employees to keep up and stay relevant with the growth of the organizations over time. The knowledge-base related activities within the organizations are managed in such a manner that enables key employees to make use of the knowledge to develop and build up their core competencies in executing the organizational tasks. It is also posited that a well-managed organizational knowledge-base allows the existing talented employees access the organizational knowledge repository for valuable information to ease the process of business decision-making and thereby, promoting the retention of key talents that further contribute to better business results of the organization.

Therefore, this paper is aimed to investigate the organizational performance of private colleges in Malaysia in association with knowledge management and to evaluate the mediating role of managing talent development and talent retention respectively on the relationship between knowledge management and organizational performance of private colleges. The next section of this paper discusses the research context which leads to hypotheses developed in accordance to the literatures reviewed on knowledge management and organizational performance. This is followed by an explanation of the research method used and the assessment of measurement and structural models by employing the PLS-SEM technique using SmartPLS 2.0 M3 software. Limitations of the study and managerial implications are also highlighted in this paper before it ends with some concluding remarks.

\section{Literatures Review and Hypotheses}

According to Chilton and Bloodgood [11], knowledge management is primarily aimed at protecting organizational knowledge from the use by competitors to exploit a competitive advantage for the organization.
Following the emergence of a knowledge-based economy in the advent of globalization, Anand et al. [12] has thus regarded knowledge management as of utmost importance to create and add value to the business. Other past studies (Whelan \& Carcary [13]; Kianto et al. [14]) have however, argued that knowledge management is a business practice that still remains in development despite of it being an effective tool to generate competitive advantage that benefits organizational performance. As knowledge management plays a prominent role within the local public higher education institutions in recent years, there is still a lack of empirical evidence on the relationship between knowledge management and organizational performance among private colleges in the context of Malaysian higher education business sector. This paper therefore hypothesizes that:

H1: There is a significant positive relationship between knowledge management and organizational performance of private colleges.

From the knowledge-based perspective, the initiative of managing knowledge that has a positive influence on the business performance of organizations has clearly been documented by numerous past studies (Turner \& Minnone [15]; Liao [16]; Andreeva \& Kianto [17]; Kianto et al. [18]; Inkinen, Kianto \& Vanhala [19]; Salami \& Mercy [20]). However, those studies in the past did not pay sufficient attention to the domain of knowledge management that links the practices of managing talent within a knowledge-intensive setting that in turn positively influences organizational performance. While organizational knowledge facilitates the way to which talents can be managed in the organization, it follows that our present study has identified management of talent as a strategic practice of managing attraction and recruitment, development and retention of talented employees as a source of competitive advantage that is critical to the business success of educational organizations. As such, the researchers have regarded that private academic institutions that maintain a well-managed organizational knowledge-base will exert a more profound effect on how the existing talents can be further developed and retained, albeit when they are recruited for longer-term organizational success. Nonetheless, the links between knowledge management with managing talent practices, namely talent development and talent retention towards organizational performance are still not adequately examined.

In order to address this gap, managing talent development and talent retention in this study are regarded as mediators on the relationship between knowledge management and organizational performance of private colleges. The mediating variables used are uniquely distinct, whereby talent development according to Dass, Muthaly and Annakis [21] is the practice of developing incumbents through the processes such as coaching, mentoring, feedback, training and development and 
challenging employees to perform their tasks and functions with competence and on the other hand, talent retention is the practice of retaining high-potential employees for a maximum period of time with the aim of maintaining a competitive organizational workforce (Oladapo [22]).Therefore, this paper hypothesizes that:

$\mathrm{H} 2$ : Knowledge management has a significant direct positive influence on talent development among private colleges.

H3: Knowledge management has a significant direct positive influence on talent retention among private colleges.

H4: Managing talent development has a significant direct positive influence on organizational performance of private colleges.

H5: Managing talent retention has a significant direct positive influence on organizational performance of private colleges.

H6: The direct relationship between knowledge management and organizational performance of private colleges is mediated by talent development.

H7: The direct relationship between knowledge management and organizational performance of private colleges is mediated by talent retention.

\section{Methodology}

A survey method using structured questionnaires as a tool to collect quantitative data for the variables of interest studied. All measurement items in this study are adapted from previously validated scales. Knowledge management comprises 14 items measuring on a 5-point Likert scale are adapted from Zack, McKeen and Singh [23] while the latent variables of managing talent development and talent retention have 6 items each that are adapted from Oehley [24] and all are measured on a 5-point Likert scale, from which 1 (strongly disagree), 2 (disagree), 3 (neither agree nor disagree), 4 (agree) and 5 (strongly agree). Meanwhile, the perceived organizational performance of private colleges is measured using 10 items on a 7-point Likert scale that are adapted from Slavkovic and Babic [25], with which 1 (strongly disagree), 2 (disagree), 3 (somewhat disagree), 4 (neither agree nor disagree), 5 (somewhat agree), 6 (agree) and 7 (strongly agree).The sampling frame is identified from the Malaysian Qualifications Register (MQR), a national list of private colleges maintained by the Malaysian Qualifications Agency (MQA). Unit of analysis is at individual level. A total of 785 sets of questionnaires were sent out to academic and non-academic staff above the executive level from 157 selected private colleges in Malaysia. The selection of these private colleges was based on a probability sampling approach to simple random sampling and a calculation of minimum sample size for this study using the technique introduced by Luck, Taylor and Robin [26], in which 157 institutions out of 390 registered private colleges with the 2017 Malaysian Qualifications Register [27] were chosen. The targeted respondents participating in this survey were comprised of senior management, departmental managers, senior executives, senior lecturers and heads of programs (HoPs) employed by these private colleges. Of the 785 questionnaires distributed, 243 were deemed valid and usable which provided the sample size to this study. A response rate of $31 \%$ was achieved. Of the 243 respondents, $40.7 \%$ of them were only involved in non-academics whereas $35.8 \%$ dealt with academic affairs and the remaining $23.5 \%$ of them were involved in both academic and non-academic tasks of the private colleges. Moreover, nearly half of the respondents $(44.4 \%)$ had 3 to 5 years of working experience in private colleges with slightly more than one-third (35\%) had worked for 6 to 10 years while the remaining $20.6 \%$ of them had been working for more than 10 years.

PLS-SEM technique using SmartPLS (M2) is deployed to analyze the data collected. In particular, the variance-based approach to PLS-SEM is used in our study to predict/explain the key target construct of organizational performance in addition to estimating path models with latent variables and their hypothesized relationships. Two stages are essentially involved in the evaluation of PLS path-models - Stage 1 addresses the assessment of measurement model, in which case a reflective measurement model for this study. If the evaluation results meet the criteria for measurement quality, researchers then proceed to the structural model evaluation in Stage 2 that involves testing the proposed hypotheses and determining the relationships among the latent variables.

\section{Results of Measurement and Structural Models}

This study begins with testing the common method variance bias using Harman's single factor test since the data was collected from a single source of information through a single questionnaire. According to Podsakoff, MacKenzie and Lee [28], common method variance bias becomes problematic when a single latent factor accounted for the majority of the variance explained. The un-rotated factor analysis has shown that the first factor is only accounted for $17 \%$ of the total $66.5 \%$ variance. This shows a latent variable is not accounted for the majority of the total variance explained. The results from the principal component analysis (PCA) have further revealed 6 factors with eigenvalues greater than 1 , which suggests that the variables studied are clearly factoralizable, as is indicated by KMO Measures of Sampling Adequacy is 0.927 (larger than 0.6) with a significant Barlett's Test of Sphericity result $($ Sig. $=0.000)$. Therefore, the results have shown that common method variance bias is not a serious problem in our study. 
The PLS algorithm is run to evaluate reliability and validity of the reflective measurement model using four main criteria, which are internal consistency reliability, indicator reliability, convergent validity and discriminant validity. Referring to the following Table 1 , one of the criteria to be initially assessed is internal consistency reliability using the measure of composite reliability (CR). The results show that the values of composite reliability ranged from 0.8841 to 0.9347 which are above the recommended threshold value of 0.8 . This has indicated the measures used to represent the constructs have achieved internal consistency reliability. The use of Cronbach's alpha as mentioned by Hair et al. [29], tends to underestimate the internal consistency reliability because it assumes all indicators loadings are equal, despite that the values of Cronbach's alpha ranging from 0.8366 to 0.9199 are acceptable.

The measurement model has also demonstrated adequate indicator reliability when each indicator's outer loading exceeds 0.708 and is statistically significant at 0.05 level. The item KM9 with loadings less than 0.708 is retained because the removal of this item will not significantly increase the value of CR. Next is convergent validity of the measurement model which is established when all the latent variables have average variance extracted (AVE) values ranging from 0.5659 to 0.6862 and all are above the critical value of 0.5 .

Table 1. Results of the Measurement Model

\begin{tabular}{|c|c|c|c|c|c|c|}
\hline Construct & Items & Loadings & AVE & Composite Reliability & T-statistics & Cronbach's Alpha \\
\hline \multirow[t]{10}{*}{ Knowledge Management } & KM5 & 0.7425 & 0.5659 & 0.9286 & 24.043 & 0.9151 \\
\hline & KM6 & 0.7878 & & & 22.047 & \\
\hline & KM7 & 0.7118 & & & 15.864 & \\
\hline & KM8 & 0.7183 & & & 14.872 & \\
\hline & KM9 & 0.6998 & & & 15.522 & \\
\hline & KM10 & 0.7806 & & & 23.455 & \\
\hline & KM11 & 0.7599 & & & 25.222 & \\
\hline & KM12 & 0.7424 & & & 16.975 & \\
\hline & KM13 & 0.7707 & & & 25.682 & \\
\hline & KM14 & 0.8017 & & & 32.319 & \\
\hline \multirow[t]{6}{*}{ Talent Development } & TD1 & 0.8198 & 0.6862 & 0.9291 & 31.689 & 0.9085 \\
\hline & $\mathrm{TD} 2$ & 0.8394 & & & 39.281 & \\
\hline & TD3 & 0.7870 & & & 23.836 & \\
\hline & TD4 & 0.8515 & & & 39.087 & \\
\hline & TD5 & 0.8310 & & & 35.172 & \\
\hline & TD6 & 0.8400 & & & 32.013 & \\
\hline \multirow[t]{5}{*}{ Talent Retention } & TR1 & 0.8253 & 0.6049 & 0.8841 & 36.594 & 0.8366 \\
\hline & TR2 & 0.7198 & & & 17.517 & \\
\hline & TR3 & 0.7291 & & & 16.634 & \\
\hline & TR4 & 0.7817 & & & 21.545 & \\
\hline & TR6 & 0.8263 & & & 29.687 & \\
\hline \multirow[t]{8}{*}{ Organizational Performance of Private Colleges } & OP3 & 0.7145 & 0.6428 & 0.9347 & 14.881 & 0.9199 \\
\hline & OP4 & 0.7090 & & & 13.784 & \\
\hline & OP5 & 0.8554 & & & 40.210 & \\
\hline & OP6 & 0.8682 & & & 41.232 & \\
\hline & OP7 & 0.8552 & & & 40.405 & \\
\hline & OP8 & 0.7985 & & & 23.896 & \\
\hline & OP9 & 0.8079 & & & 24.288 & \\
\hline & OP10 & 0.7888 & & & 23.972 & \\
\hline
\end{tabular}

In addition, discriminant validity of the constructs is evaluated using two measures which are i) Cross-Factor Loadings and ii) Fornell-Larcker's Criterion. The measurement model exhibits discriminant validity when i) the indicator's loadings on the respective construct are highest compared to all of its loadings on other constructs and ii) the square root of each construct's AVE exceeds the correlations between the construct and all other constructs in the model. The results 
of all the constructs discriminant validity are presented in the following Table 2 and Table 3 respectively.

Table 2. Output of Cross-Factor Loadings

\begin{tabular}{|c|c|c|c|c|c|}
\hline & Knowledge Management & Org Perf Prvt Colleges & Talent Development & Talent Retention & T-Statistics \\
\hline KM10 & 0.7806 & 0.5143 & 0.5385 & 0.5017 & 23.455 \\
\hline KM11 & 0.7599 & 0.5632 & 0.5311 & 0.4525 & 25.222 \\
\hline KM12 & 0.7424 & 0.5673 & 0.5840 & 0.5043 & 16.975 \\
\hline KM13 & 0.7707 & 0.5101 & 0.6222 & 0.4969 & 25.682 \\
\hline KM14 & 0.8017 & 0.5962 & 0.6039 & 0.5518 & 32.319 \\
\hline KM5 & 0.7425 & 0.4288 & 0.5830 & 0.5409 & 24.043 \\
\hline KM6 & 0.7878 & 0.5538 & 0.5293 & 0.4847 & 22.047 \\
\hline KM7 & 0.7118 & 0.4252 & 0.3741 & 0.3501 & 15.864 \\
\hline KM8 & 0.7183 & 0.4387 & 0.3712 & 0.3926 & 14.872 \\
\hline KM9 & 0.6998 & 0.4481 & 0.4015 & 0.4135 & 15.522 \\
\hline OP10 & 0.5478 & 0.7888 & 0.5063 & 0.4660 & 23.972 \\
\hline OP3 & 0.4431 & 0.7145 & 0.3136 & 0.2988 & 14.881 \\
\hline OP4 & 0.4832 & 0.7090 & 0.4177 & 0.3355 & 13.784 \\
\hline OP5 & 0.5894 & 0.8554 & 0.5399 & 0.4983 & 40.210 \\
\hline OP6 & 0.5875 & 0.8682 & 0.5710 & 0.5384 & 41.232 \\
\hline OP7 & 0.5698 & 0.8552 & 0.5172 & 0.5028 & 40.405 \\
\hline OP8 & 0.5329 & 0.7985 & 0.5168 & 0.4478 & 23.896 \\
\hline OP9 & 0.5660 & 0.8079 & 0.4700 & 0.4245 & 24.288 \\
\hline TD1 & 0.5911 & 0.5326 & 0.8198 & 0.5996 & 31.689 \\
\hline TD2 & 0.5889 & 0.4597 & 0.8394 & 0.6226 & 39.281 \\
\hline TD3 & 0.5299 & 0.4628 & 0.7870 & 0.5543 & 23.836 \\
\hline TD4 & 0.6119 & 0.5825 & 0.8515 & 0.6414 & 39.087 \\
\hline TD5 & 0.5373 & 0.4544 & 0.8310 & 0.5674 & 35.172 \\
\hline TD6 & 0.5911 & 0.5154 & 0.8400 & 0.6349 & 32.013 \\
\hline TR1 & 0.5849 & 0.5286 & 0.6385 & $\mathbf{0 . 8 2 5 3}$ & 36.594 \\
\hline TR2 & 0.3705 & 0.3759 & 0.4081 & 0.7198 & 17.517 \\
\hline TR3 & 0.4544 & 0.3827 & 0.5219 & 0.7291 & 16.634 \\
\hline TR4 & 0.4895 & 0.3772 & 0.6161 & $\mathbf{0 . 7 8 1 7}$ & 21.545 \\
\hline TR6 & 0.5203 & 0.4680 & 0.6199 & 0.8263 & 29.687 \\
\hline
\end{tabular}

Table 3. Fornell-Larcker's Criterion

\begin{tabular}{|c|c|c|c|c|}
\hline & Knowledge Management & Org Perf Prvt Colleges & Talent Development & Talent Retention \\
\hline Knowledge Management & $\mathbf{0 . 7 5 2 3}$ & & & \\
\hline Org Perf Prvt Colleges & 0.6768 & $\mathbf{0 . 8 0 1 8}$ & & \\
\hline Talent Development & 0.6959 & 0.6082 & $\mathbf{0 . 8 2 8 4}$ & \\
\hline Talent Retention & 0.6310 & 0.5557 & 0.7301 & $\mathbf{0 . 7 7 7 8}$ \\
\hline
\end{tabular}

Having examined the measurement model, this paper proceeds to evaluate the structural model when reliability, convergent validity and discriminant validity of the measurement scales are satisfactorily achieved. In assessing the structural model of this study, a variance-based PLS-SEM method is used to predict the endogenous latent constructs and to test the hypothesized relationships between latent constructs. The structural model is then evaluated using the coefficients of determination $\left(R^{2}\right)$, the level and significance of the path-model coefficients. As recommended by Hair et al. [30], 5000 bootstrap samples from 243 observed cases originally used with a 'no sign change option' to estimate the path-model coefficients and their significance. The diagram below illustrates the structural model evaluation with the path-model coefficients shown for this study. 


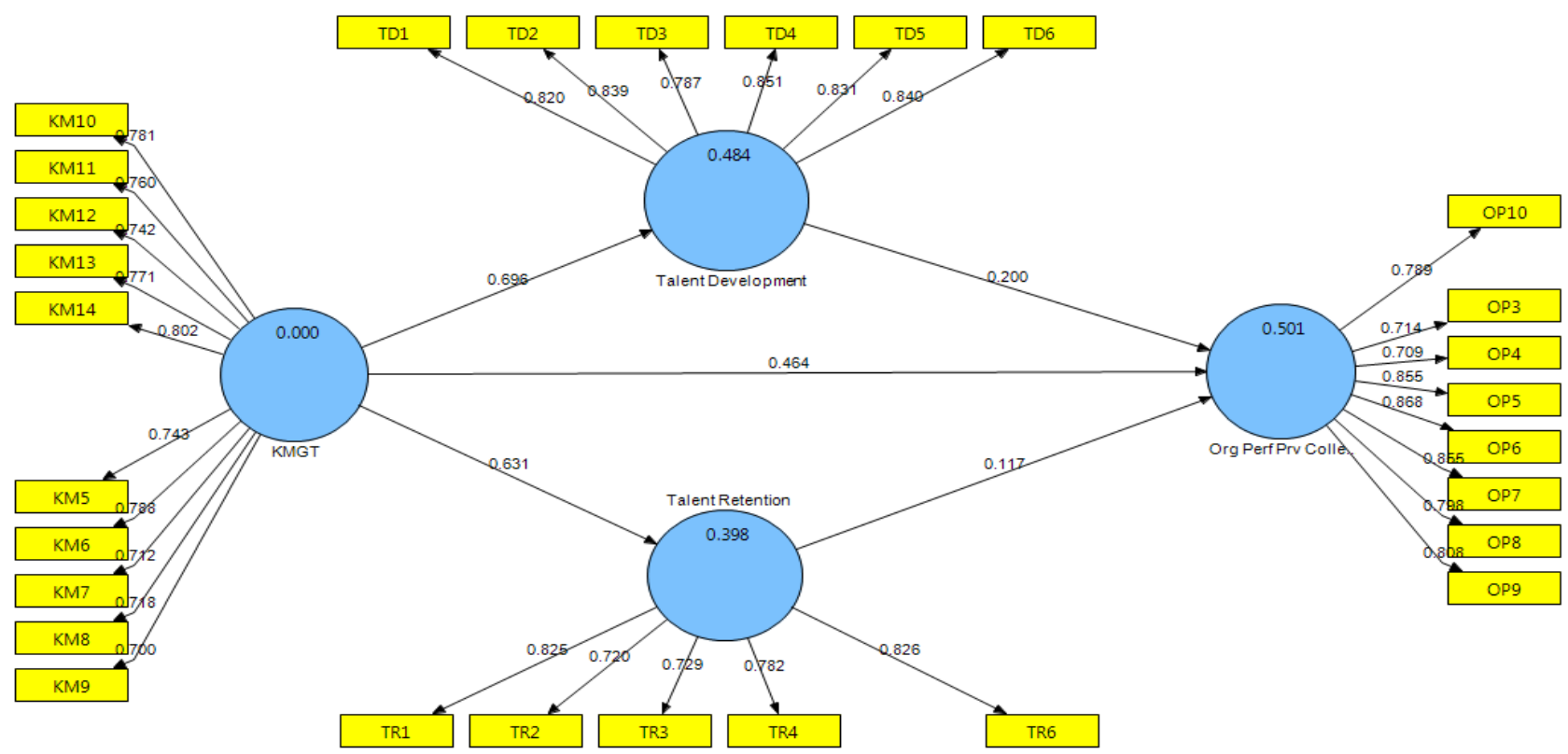

Figure 1. PLS Path-Model Evaluation

In determining the $R^{2}$ values of the endogenous latent variables, the model above shows that $48.4 \%\left(R^{2}=0.484\right)$ of the amount of variance of talent development and that $39.8 \%\left(R^{2}=0.398\right)$ of talent retention are influenced by knowledge management while $50.1 \%\left(R^{2}=0.501\right)$ of the amount of variance of organizational performance of private colleges is explained by the model. Hence, the model provides a moderately strong predictive power. With the use of omission distance, $\mathrm{D}=7$ and 243 cases observed in our study, a subsequent run on the blindfolding procedure in SmartPLS 2 further reveals the resulting cross-validated redundancy $Q^{2}$ values that are above zero for all endogenous constructs and thus, providing support for the model's predictive accuracy.

To further investigate the hypothesized relationships between latent constructs within the structural model, Table 4 below highlights the results of hypotheses testing in which the proposed hypotheses $\mathrm{H} 1, \mathrm{H} 2, \mathrm{H} 3$ and $\mathrm{H} 4$ are supported, all of which indicate the expected positive sign direction with their path-coefficient estimates $(\beta)$ ranging from 0.2001 to 0.6959. Overall, knowledge management and talent development are significant predictors contributing to organizational performance of private colleges. In addition, knowledge management is shown to have predicted a significant positive influence on talent development and talent retention respectively. However, managing talent retention is found to have not significantly related to organizational performance of private colleges and hence, the proposed hypothesis $\mathrm{H} 5$ is not supported.

Table 4. Significance testing results of the structural model path coefficients

\begin{tabular}{|c|c|c|c|c|c|}
\hline Hypothesis & Hypothesized Relationship & Path Coefficient, $\beta$ & Standard Error (SE) & $\mathrm{t}$-value & Decision \\
\hline H1 & KMGT -> Org Perf Prvt Colleges & 0.4638 & 0.0736 & $6.298^{* *}$ & Supported \\
\hline H2 & KMGT -> Talent Development & 0.6959 & 0.0430 & $16.183^{* *}$ & Supported \\
\hline H3 & KMGT -> Talent Retention & 0.6310 & 0.0542 & $11.633^{* *}$ & Supported \\
\hline H4 & Talent Development -> Org Perf Prvt Colleges & 0.2001 & 0.0932 & $2.147^{*}$ & Supported \\
\hline H5 & Talent Retention -> Org Perf Prvt Colleges & 0.1170 & 0.0880 & 1.330 & Not Supported \\
\hline
\end{tabular}

Note: ${ }^{* *} p<0.01, * p<0.05$

\section{Evaluation of the Mediation Relationship in PLS Path-model}

Within the PLS path-model, mediation is a situation in which a mediator variable to some extent absorbs the effect of an exogenous on an endogenous latent variable. In conducting mediation analysis therefore, this paper follows Preacher and Hayes [31] to bootstrap the sampling distribution of the indirect effect. Bootstrapping as stated by Hair et al. [32] is a non-parametric resampling procedure for testing mediation effects that makes no assumptions of normality of the sampling distribution and is applicable to small sample sizes with more confidence. The significance of the indirect effect is tested using a bootstrapping routine with 243 observed cases, 5000 subsamples and a 'no sign change option' in SmartPLS 2. 
The empirical results of this study shown in Table 5 below have highlighted the role of talent development (TD) in significantly mediating the relationship between knowledge management (KMGT) and organizational performance of private colleges. Therefore, the proposed hypothesis H6 is supported. On the other hand, talent retention (TR) is found to have not significantly mediated the relationship between knowledge management (KMGT) and organizational performance of private colleges. Hence, the proposed hypothesis $\mathrm{H7}$ is not supported.

Table 5. Significant testing results of the mediation relationship

\begin{tabular}{|c|c|c|c|c|c|}
\hline Hypothesis & Hypothesized Relationship & Path Coefficient, $\beta$ & Standard Error (SE) & t-value & Decision \\
\hline H6 & KMGT -> TD -> Org Perf Prvt Colleges & 0.1392 & 0.0668 & $2.084^{*}$ & Supported \\
\hline H7 & KMGT -> TR -> Org Perf Prvt Colleges & 0.0738 & 0.0565 & 1.306 & Not Supported \\
\hline
\end{tabular}

Note: ${ }^{*} p<0.05$

Based on Preacher and Hayes [33], the following Table 6 highlights the indirect effects 95\% Boot CI: [LL=0.0083, $\mathrm{UL}=0.2701]$ does not fall in between a zero within the confidence interval at the given significance level of $5 \%$ and thus, statistically confirming the mediation effects of talent development (TD). This indicates talent development, TD as a mediator variable absorbs some of the direct effects of knowledge management on organizational performance of private colleges. The empirical findings have nevertheless revealed no mediation that occurs on the effect of talent retention in mediating the relationship between knowledge management and organizational performance of private colleges.

Table 6. Bootstrapped confidence interval

\begin{tabular}{|c|c|c|c|c|c|}
\hline Relationship & Indirect Effect & Standard Error (SE) & Lower Limit (LL) & Upper Limit (UL) & $\begin{array}{c}\text { 95\% Bootstrapped } \\
\text { Confidence Interval }\end{array}$ \\
\hline KMGT -> TD -> Org Perf Prvt Colleges & 0.1392 & 0.0668 & 0.0083 & 0.2701 & {$[\mathrm{LL}=0.0083, \mathrm{UL}=0.2701]$} \\
\hline KMGT -> TR -> Org Perf Prvt Colleges & 0.0738 & 0.0565 & -0.0369 & 0.1845 & {$[\mathrm{LL}=-0.0369, \mathrm{UL}=0.1845]$} \\
\hline
\end{tabular}

In determining the strength of mediation, the Variance Accounted For (VAF) assessment by Hair et al. [34] is then used whereby VAF is equal to the indirect effect divided by the total effect (i.e. direct effect + indirect effect). This value is ranged between 0 and 1 or $0 \%$ to $100 \%$ which indicates a stronger mediation occurs when the results are higher. According to Hair et al. further, it is assumed partial mediation when the assessment of VAF is larger than $20 \%$ but less than $80 \%$ (i.e. $20 \%<\mathrm{VAF}<80 \%$ ) and with VAF in this study is equal to $0.231(0.1392 / 0.6030)$ or $23.1 \%$ and as such, we conclude that talent development (TD) as the mediator variable partially mediates the relationship between knowledge management and organizational performance of private colleges.

\section{Limitations}

This present study is not without any limitations. A wider sample that covers both public and private universities in Malaysia with multiple responses from individuals and management levels could be included in future study to be more generalized to the higher education industry in the country. The same research study can also be carried out by using other mediating or even moderating variables such as the use of innovative technology and government support to understand better the organizational performance of private colleges in relation with knowledge management.

\section{Managerial Implications}

This study benefits both researchers and business practitioners by highlighting the importance of knowledge management in private colleges within the Malaysian higher education industry. The higher the level of activities and practices in managing knowledge, the better outcome will be to the organizational performance of private colleges in Malaysia. When these private academic institutions manage their organizational-related knowledge base well, they are better able to develop and retain talented employees in meeting current and future business needs. Since the findings further reveal that talent development mediates the relationship between knowledge management and organizational performance of private colleges, it is therefore in the interest of the Malaysian private colleges to invest adequate resources in establishing a well-functioning knowledge management mechanism such as the setting up of network multimedia and e-learning facilities to drive the development of talented workforce in enhancing their knowledge and skills competencies that in turn contributing to the long-term business success.

\section{Conclusions}

This present study adds to the literature of knowledge management in relation to managing talent practices and organizational performance. It fills the gap by addressing organizational performance that is linked with knowledge management mediated by managing talent practices, 
namely talent development and talent retention respectively. In light of this, empirical findings of this study have highlighted that knowledge management and talent development are influential to the organizational performance of private colleges. Interestingly, talent development rather than talent retention is ultimately linked to knowledge management that has exerted a significant positive influence over organizational performance of Malaysian private colleges. Hence, talent development is identified as the potential linkage that transmits the effects of managing knowledge towards organizational performance of private colleges over time. Towards this end, the development of talented employees that is built upon knowledge management within the institution becomes imperative in delivering a sustainable organizational performance of Malaysian private colleges.

\section{REFERENCES}

[1] Nasiruzzaman, M., Qudaih, H.A., \& Dahlan, A.R. (2013). Project success and knowledge management practices in Malaysian institutions of higher learning. Journal of Education and Vocational Research, 4(5), 159-164.

[2] Nawaz, M.N., \& Gomes, A.M. (2014). Review of knowledge management in higher education institutions. European Journal of Business and Management, 6(7), 71-79.

[3] Mohamad, R., Manning, K., \& Tatnall, A. (2013). Knowledge management in university administration in Malaysia. In Passey, D., Breiter, A., \& Visscher, A. (Eds.)., Next Generation of Information Technology in Educational Management. IFIP Advances in Information and Communication Technology, Heidelberg, Berlin.

[4] Attallah, M., Athab, M., Abed, W.J., \& Ali, N. (2015). Review of knowledge management success factors in higher educational organizations. Journal of Advanced Computer Science and Technology Research, 5(3), 83-92.

[5] Norulkamar, U., \& Hatamleh, A. (2014). A review of knowledge sharing barriers among academic staff: A Malaysian perspective. Sains Humanika, 2(2), 87-91.

[6] Aziz, N.F., Lotfi, N.A., \& Dahlan, A.K. (2015). Empirical study on the culture of successful knowledge creation and knowledge sharing in institute of higher learning. International Journal of Management and Commerce Innovations, 3(1), 298-303.

[7] Yusoff, M.Y., \& Mahmood, A.K., \& Jaafar, J. (2012). A study of knowledge management process and knowledge management enabler in a Malaysian community college. Journal of Knowledge Management Practice, 13(1), 1-10.

[8] Demchig, B. (2015). Knowledge management capability level assessment of the higher education institutions: Case study from Mongolia. Procedia Social and Behavioral Sciences, 17(4), 3633-3640.

[9] Yeh, Y. (2010). The implementation of knowledge management system in Taiwan's higher education. Journal of College Training and Learning, 2(9), 35-42.

[10] Schroevers, M., \& Hendriks, P. (2012). Talent management in knowledge-intensive organizations. In H.T.Hou (Ed.)., New research on knowledge management models and methods (pp.355-370). Open Science, China: InTech Publsiher.

[11] Chilton, M.A., \& Bloodgood, J.M. (2013). Knowledge management and competitive advantage: Issues and potential solutions. Information Science Reference: IGI Global.

[12] Anand, A., Kant, R., Patel, D.P., \& Singh, M.D. (2012). Knowledge management implementation: A predictive model using an analytical hierarchical process. Journal of Knowledge Economy, 6, 48-71.

[13] Whelan, E., \& Carcary, M. (2011). Integrating talent and knowledge management: Where are the benefits? Journal of Knowledge Management, 15(4), 675-687.

[14] Kianto, A., Ritala, P., Spender, J.C., \& Vanhala, M. (2014) The interaction of intellectual capital assets and knowledge management practices in organizational value creation. Journal of Intellectual Capital, 15(3), 362-375.

[15] Turner, G., \& Minnone, C. (2010). Measuring the effects of knowledge management practices. Electronic Journal of Knowledge Management, 8(1), 161-170.

[16] Liao, Y.S. (2011). The effect of human resource management control systems on the relationship between knowledge management strategy and firm performance. International Journal of Manpower, 32(5), 494-511.

[17] Andreeva, T., \& Kianto, A. (2012). Does knowledge management really matter? Linking knowledge management practices, competitiveness and economic performance. Journal of Knowledge Management, 16(4), 617-636.

[18] Kianto, A., Ritala, P., Spender, J.C., \& Vanhala, M. (2014). The interaction of intellectual capital assets and knowledge management practices in organizational value creation. Journal of Intellectual Capital, 15(3), 362-375.

[19] Inkinen, H., Kianto, A., \& Vanhala, M. (2015). Knowledge management practices and innovation performance in Finland. Baltic Journal of Management, 10(4), 432-455.

[20] Salami, E., \& Mercy, O. (2015). Knowledge management and organizational performance. Retrieved from http://dx.doi.org/10.2139/ssm.2612526.

[21] Dass, M., Muthaly, S., \& Annakis, J. (2015). Talent culture's role in talent development among academics: Insights from Malaysian government-linked universities. Contemporary Issues in Business and Government, 21(1), 46-71.

[22] Oladapo, V. (2014). The impact of talent management on retention. Journal of Business Studies Quarterly, 5(3), 19-36.

[23] Zack, M., McKeen, J., \& Singh, S. (2009). Knowledge management and organizational performance: An exploratory survey. Journal of Knowledge Management, 13(6), 392-409.

[24] Oehley, A.M. (2007). The development and evaluation of a partial talent management competency model. (Unpublished master's thesis). Stellenbosch University, South Africa. 
[25] Slavkovic, M., \& Babic, V. (2014). Knowledge management, innovativeness and organizational performance: Evidence from Serbia. Economic Annals, LV111(199), 85-107.

[26] Luck, D.J., Taylor, W.G., \& Robin. (1987). Marketing research. Englewood Cliffs: Prentice Hall.

[27] Malaysian Qualifications Agency. (2017). Malaysian Qualifications Register, MQR. Retrieved from www2.mqa.gov.my/mqr/english/eakrbyiptskolej.cfm?StarR $\mathrm{ow}=1$.

[28] Podsakoff, P.M., MacKenzie, S.B., \& Lee, J.Y. (2003). Common method biases in behavioral research: A critical review of the literature and recommended remedies. Journal of Applied Psychology, 88(5), 879-903.

[29] Hair, J.F., Hult, G.M., Ringle, C.M., \& Sarstedt, M. (2014). A primer on partial least squares structural equation modelling. Thousand Oaks, CA: Sage.
[30] Hair, J.F., Hult, G.M., Ringle, C.M., \& Sarstedt, M. (2014) $A$ primer on partial least squares structural equation modelling. Thousand Oaks, CA: Sage.

[31] Preacher, K.J., \& Hayes, A.F. (2008). Asymptotic and resampling strategies for assessing and comparing indirect effects in simple and multiple mediator models. Behaviour Research Methods, 40(3), 879-891.

[32] Hair, J.F., Hult, G.M., Ringle, C.M., \& Sarstedt, M. (2014). A primer on partial least squares structural equation modelling. Thousand Oaks, CA: Sage.

[33] Preacher, K.J., \& Hayes, A.F. (2008). Asymptotic and resampling strategies for assessing and comparing indirect effects in simple and multiple mediator models. Behaviour Research Methods, 40(3), 879-891.

[34] Hair, J.F., Hult, G.M., Ringle, C.M., \& Sarstedt, M. (2014). $A$ primer on partial least squares structural equation modelling. Thousand Oaks, CA: Sage. 